

RESEARCH PAPER

\title{
Analyzing Graphological Deviation in Pakistani Television Commercials
}

Muhammad Mooneeb Ali ${ }^{1}$ Tayyaba Yasmin ${ }^{2}$ Muammad Nadeem Anwar ${ }^{3}$

1. Lecturer, Department of English, Government College of Science Wahdat Road Lahore, Punjab, Pakistan

2. Lecturer, Department of English, University of Education Lahore, Punjab, Pakistan

3. Lecturer, Department of English, Government College of Science, Wahdat Road, Lahore, Punjab, Pakistan

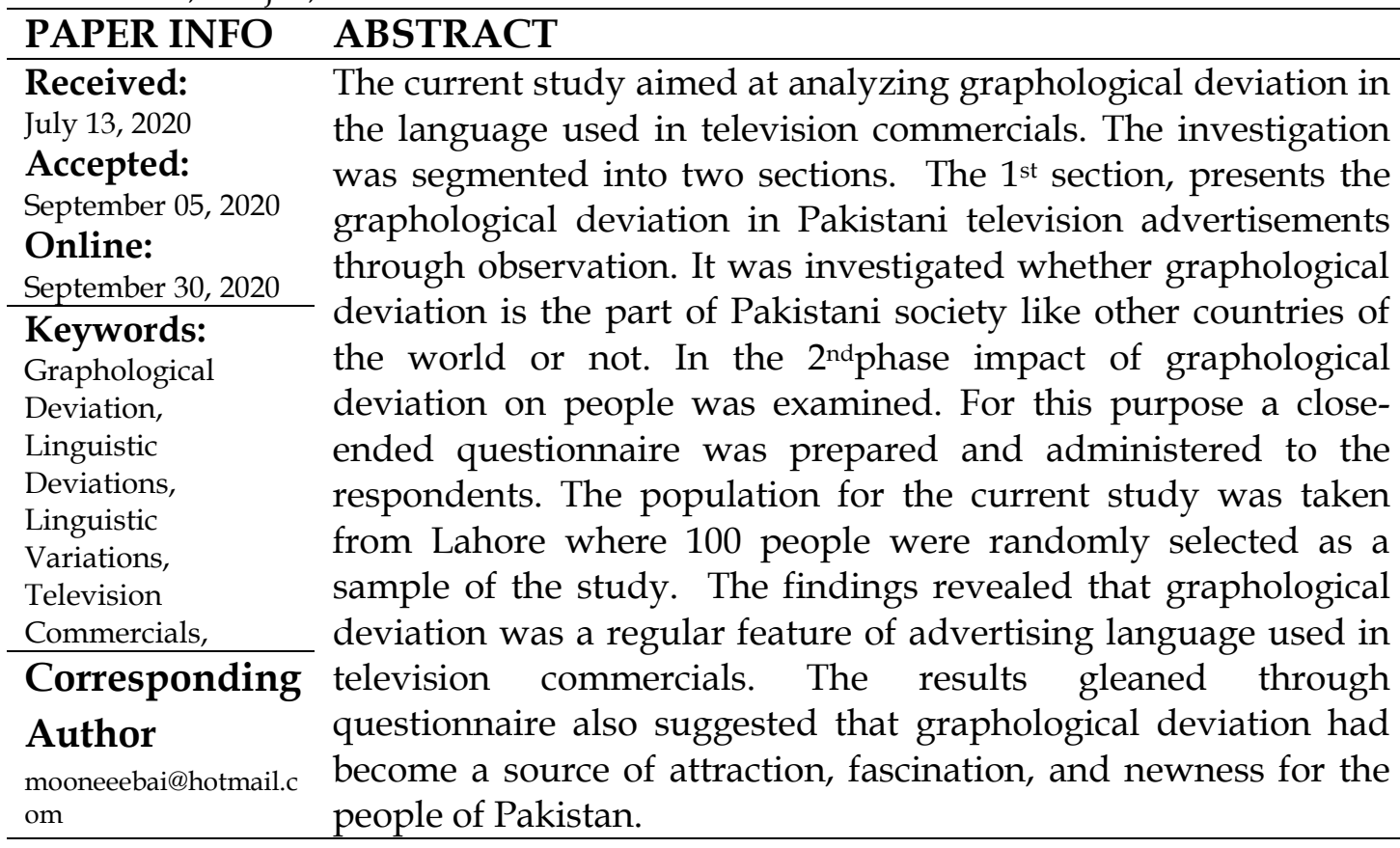

\section{Introduction}

According to Leech (1969) there are eight kinds of linguistic deviations at different levels: Lexical, Grammatical, Phonological, Graphological, Semantic, dialectical, deviation of Register, and deviation of historical period. Here in the current research the focal point is to examine graphological deviation. Before we discuss in detail about the current research let us first view what is graphology? And later we will discuss some important aspects of graphological deviation.

\section{Graphology}

The term graphology refers to the study of graphical features of language. McIntosh (1961) finds graphology similar to phonology. He takes graphology "in a 
sense which is intended to answer, in the realm of written language, to that of 'phonology' in the realm of spoken language" (pp.107). Halliday, McIntosh and Strevens (1964) later on widened the scope of the term graphology and also joined it with spellings, pronunciations, punctuations and other related graphical sources of language. Graphology is the written system of a language (not the rules, which govern the systematic use of words and structures, in order to create meaningful sentences), rather it is the hand writing system, or the system of typed / composed form of writing, wherein we have to take care of the rules of punctuations, spacing, and capitalization.

\section{Graphological deviation}

Graphological deviation can be taken as a linguistic deviation which does not consider the speech, punctuations, capitalizations, parenthesis, synthesis, and jumbling of the words with numbers etc. We can say that graphological deviation is the violation of the rules of the written systems of a language.

\section{Graphological deviation in advertisements}

In advertisements one can easily view this feature of graphological deviation. Some studies such as the study conducted by Raj(2015), Ren and Yu (2013) show that in the field of television advertisements no one can ignore the value of graphological deviation. Graphological deviation is a significant element and reliable feature of advertisement these days. Graphological deviation is not only restricted to be used in neon sign boards but they are also an integral feature of television commercials.

\section{Literature Review}

Language is a unique phenomenon of human beings which distinguish it from other species. Human beings rely on language to express themselves, communicate with others, and know the world. As early as more than two thousand years ago, the ancient Greek scholars have begun to study language. Till now language has become the central topic of western humanities. Not only linguists, but also more and more philosophers, psychologists, sociologists and scholars of other fields have begun to pay attention to language. According to Chomsky (1957) the most distinguishing feature of human language is "productivity" or "creativity", that is to say, human beings can produce and understand an infinite number of sentences with a limited set of grammatical rules and words. The mode of communication of human language depends upon different aspects i.e. written spoken reading and listening. All these skills work in tandem and are connected with one another. Amongst all these communicative skills writing is one of the powerful skills of communication amongst human beings. No one can ignore the value of writing as it serves and facilitates in all genres and areas of communication. When one talks about the affectivity of writing, this skill is the most pivotal force in all the fields of sciences, arts and mass communication (Geiser \& Studley, 2001). Writing has never been consistent. Since its origin there are numerous changes that 
occurred in written language. So the study of handwriting is called graphology which is a linguistic level of the analysis that comprises the study of graphic aspects of language (Jimenez, 2015).

Deviation can be of different types however Leech (1969) has divided linguistic deviation into eight types.

\section{Lexical Deviation}

Lexical deviation refers to the deviation in lexicon. A good example of lexical deviation is neologism. Neologism means the invention and inclusion of new words. According to Leech (1969) neologism is not merely a violation of lexical rules, rather an existing rule is applied with greater generality than is customary: that the usual limitations on its process are waived in a given instance. The most common processes of word-formation are affixation and compounding.

\section{Grammatical Deviation}

Let us look at the second type of deviation which is grammatical deviation. According to Leech (1969) the morphological deviation is rare but the syntactic deviation is a normal phenomenon. There are two types of structures i.e. surface and deep structure. The surface structure deals with the phonological aspect whereas the deep structure deals with semantic aspect.

\section{Phonological Deviation}

This type of deviation according to Leech (1969) works like sometimes with the deletion of initial word as in aphesis i.e. for it is 'tis' sometimes the deletion of central word like for never one can use ne'er), and sometimes the deletion of the last part like for often one can use oft

\section{Graphological Deviation}

Pronunciation is dependent upon spellings so any spelling represents pronunciation, any oddness in spelling will affect the oddness in pronunciation as well. Further there are some deviation in graphology which are known as graphological deviation which does not affect the speech like capitalization, jumbling up words, adding two words to make one and parentheses usage.

\section{Semantic Deviation}

Looking at the semantic deviation it can be said that it refers to the point where sometimes apparently meaningless sentences have some particular meaning in some specific contexts. Leech (1969) states that sometimes the face value or apparent scenario of the word does have an underlined significant and powerful meaning 


\section{Dialectal Deviation}

Dialectal deviation refers to the term where some deviations in writing are generally accepted in some of the dialects only rather than in standard language. They are some words which are generally accepted in some different dialects but are unacceptable in the standard language. In another case a deviation in one dialect is usually unacceptable in another dialect of the same language (Ren \&Yu, 2013)

\section{Deviation of Register}

Leech (1966) says that an important aspect in deviation is the deviation of register which means a variation in the varieties of different languages. Register means the specific variety in any language which is only restricted to any specific profession. So the deviation in register is sometimes accepted by the specific users of the language and sometimes it is unacceptable.

\section{Historical Deviation}

Leech (1969) calls historical deviation archaism and defines it as the continued existence of the past into the language of present time, in this kind of deviation the writer gives references of some words and structures which are not the part of the current language now. They are not in use today but were the part of the language in history. The use of these kinds of words, alphabets does create an impact on the people.

\section{Theoretical Framework}

The theoretical framework for the current studies comes from the theory presented by Leech (1969) who divides the language into three main segments
1) realization
2) form
3) Semantic

The realization can be realized though graphology and phonology, the second aspect is form which envelopes lexical items grammar and the last aspect is semantics which the cognitive and denotative meanings. So talking about graphology it can be taken as the epitome of phonology when it comes to writing. So, both are inter-connected with eachother.Thusboth levels are attached to each other, and affect each other. Leech and Short (1981), say that graphology is asubstitute aspect and form of understanding phonology. Leech and Short (1981) state that the layers of the organization related to the speech and writing follows a cycle in which the Speech WritingSpeaker encodes Hearer decodes Writer encodes Reader Decodes. 


\section{Past Researches on Graphological Deviation}

Prakash and Dhawan(2017) conducted a study in which linguistic deviations were studied in the genre of newspapers. The corpus selected was 450 headlines of different news in India and it was found out that linguistic graphological deviation exists in the newspaper headlines in India. Similarly Widayanti, (2014) investigated the linguistic deviation of a poem "The Ruined Maid" by Thomas Hardy. The aim was to find out linguistic deviation in a work of poetry. It was explored that because the author wanted to make the poem eye catching, attractive and unique so he frequently used linguistic deviations in his poem. The major linguistic deviations in the poem were lexical, grammatical and graphological deviations. Ajiroghene and Umukoro (2015) conducted an investigation to find out linguistic markers in the print advertisements. In the particular case study 4 advertisements were chosen to view the linguistic markers and it as exploded that linguistic markets like capitalization, change in the layout, punctuations and mixing of words with numbers are a common trend, the research also found out that all these deviations are done to persuade people and to catch the attention of the consumers. Likewise a study by Mahmud and Mahmud (2017) viewed linguistic deviation in television commercials. They investigated this aspect through analyzing eight television commercials and concluded that the linguistic deviation especially the graphological deviation is a key aspect in the language of television commercials. They also explored that television commercials are structured in a way to create positive impact on the viewers. Similarly a study conducted by Saleem (2012) also looked into the graphological deviations but in the genre of poetry i.e. the poem "AshWednesday" by T.S.Eliot. It was explored that the graphological norms like parenthesis, omission, punctuations, capitalization were the part of the poem and the writer frequently deviated from the written norms of language to attract the readers.

Review of the related studies conducted in the past suggests that Aditya, et. al. (2017) examined linguistic deviation in newspaper headlines, Widyanti (2014) and Saleem (2012) investigated linguistic and graphological deviation respectively in the genre of poetry, Ajroghene and Umukoro (2015), and Mahmud and Mahmud. (2017) conducted research on linguistic markers and linguistic deviation in advertisements and television commercials respectively. However, there is dearth of research as regards graphological deviation found in Pakistani television commercials. So, in order to fill the research gap the current study aims to find out the use of graphological deviation in the genre of advertisements. In the present investigation the researchers' focus is on television commercials only to find out the presence of graphological deviation in Pakistani society and later on to find out the impact of these deviations on the people of Lahore (Pakistan). 


\section{Material and Methods}

\section{Research Design}

According to Guyette (1983) quantitative research supports survey method which is a way of data collection in a persistent way. It is helpful for writing down existing prevailing conditions of a community, some features of population, and the opinion of the people. The research design utilized for the current study was quantitative.

\section{Population of the study}

The population of the current study was taken from Lahore which is capital city of the biggest province of Pakistan namely Punjab. The sample consists of 100 peoplebelonging to different regions of Lahore who were selected using simple random sampling method. To make homogeneity of the research there was no specific gender that was focused as population and sample for the study.

\section{Instruments}

In this specific study two instruments were used to collect data. Initially it was observation and later questionnaire. According to Marshall and Rossman (1989) observation is the systematic description of events, behaviors, and artifacts in the social setting chosen for study. The researchers, in the current study, observed Pakistani television advertisements for three consecutive days.The data thus collected was transcribed and used for data analysis. The second instrument used was the questionnaire. Mathers, Fox and Hunn (2009) state that questionnaire is a very significant tool for the collection of huge data from the individuals. Bulmer (2004) also advocates the effectiveness of questionnaire as a tool. He is of the view that it is an effective tool used in social sciences for gathering and collecting certain information like, attitudes, perceptions, behaviors, reasons and beliefs about the topic is under research and investigation. The questionnaire, comprised of 10 constructs was distributed to 100 different people of Lahore.

\section{Data Collection Procedure}

In the current study two instruments were used to collect data. Initially for observation purposes three Pakistani television channels (Express News, Dunya News and City 42) were selected for collecting data. These channels were selected by using simple random sampling technique. The time for observing television commercials was from $7 \mathrm{pm}$ to $9 \mathrm{pm}$ which was chosen through convenience of the researcher. The process of observation continued for three days and total time duration for television commercials were 396 minutes. A corpus of 549 television commercials was collected to find out the percentage of graphological deviation in advertisements. Later in the second phase a survey method was used in which 
questionnaire was implied as a tool to collect the opinions of the people living in Lahore regarding the effect of graphological deviation on them.

\section{Results and Discussion}

The corpus collected from the three randomly chosen television commercials from 7 p.m. to 9 p.m. for three days revealed numerous facts. The corpus thus made was used for picturing the percentages of graphological deviations. Table 1 represents the graphological deviations in television commercials.

Table 1

Representation of graphological deviations in television commercials

\begin{tabular}{|c|c|c|c|c|c|c|c|}
\hline$\stackrel{\vec{\Xi}}{\hat{0}}$ &  &  & 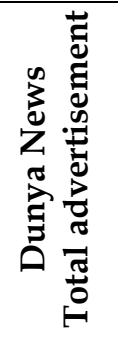 & 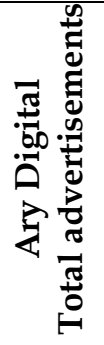 & 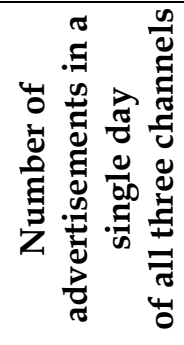 & 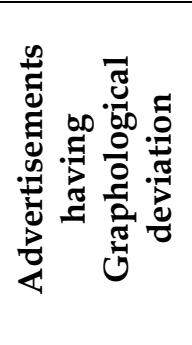 & 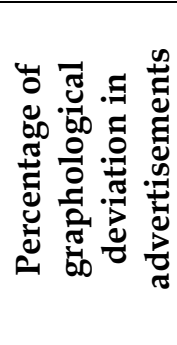 \\
\hline 1 & 2 Hours & 59 & 60 & 60 & 179 & 110 & 63.95 \\
\hline 2 & 2 Hours & 57 & 58 & 58 & 173 & 111 & 64.53 \\
\hline 3 & 2 Hours & 58 & 59 & 60 & 177 & 110 & 63.95 \\
\hline
\end{tabular}

The results reflected in table 1 reveals that the occurrence of graphological deviation is vivid in the television commercials in Pakistani electronic media. The researchers found several examples from the corpus of 549 commercials which were collected in three days from 7 p.m. to 9 p.m.it can be viewed that combing all the three channels there were 179 commercials presented in day one, in which the commercials having graphological deviation are 110. Similarly the descriptions of other days are also mentioned in table 1.

The percentage of graphological deviation in television commercials of the three days reflect that there is a strong use and frequent deviation from written language rules in television commercials in Pakistani electronic media. The percentage of day 1 and day 3 are 63.95 whereas the percentage of day 2 is 64.53 . This percentage expresses the inclination of television commercials towards graphological deviation and it clearly reflects that the use of catchy words, alteration, capitalization and other features of deviation are being followed by Pakistani commercials as well. The above table also reflects that like other countries of the world graphological deviation is used in media discourse especially commercials. Most of the commercials use graphological deviation as a tool to attract spectators' attention. Graphological deviation in Pakistani television commercials, are in the form of

1. written in Roman script 
2. Unexpected capitalization

3. Shaping up of certain words/ letters

4. Merging of letters

5. Intentionally planted Wrong spelling but right pronunciation

Some of the examples of graphological deviation taken from television commercials are,

- Digital Distrikt

- Options

- Nishat Linen.

- Yogolicious,

- $\mathrm{X} 2$

- Habitt

- TARIQ CARZ

- Haveli

- Chocholicious,

- Pizaario

- Foodyz

- AyesHa's

- Bodeolution

- KIPS

All these examples and photographs vividly exemplify the presence of deviation of language in advertisement. It also reflects that the language deviation is a common trend in Pakistani media.

The second phase of the research talks about the impact of graphological deviation on the respondents i.e. the people of Lahore. The details of the questionnaire and its responses are given here below:

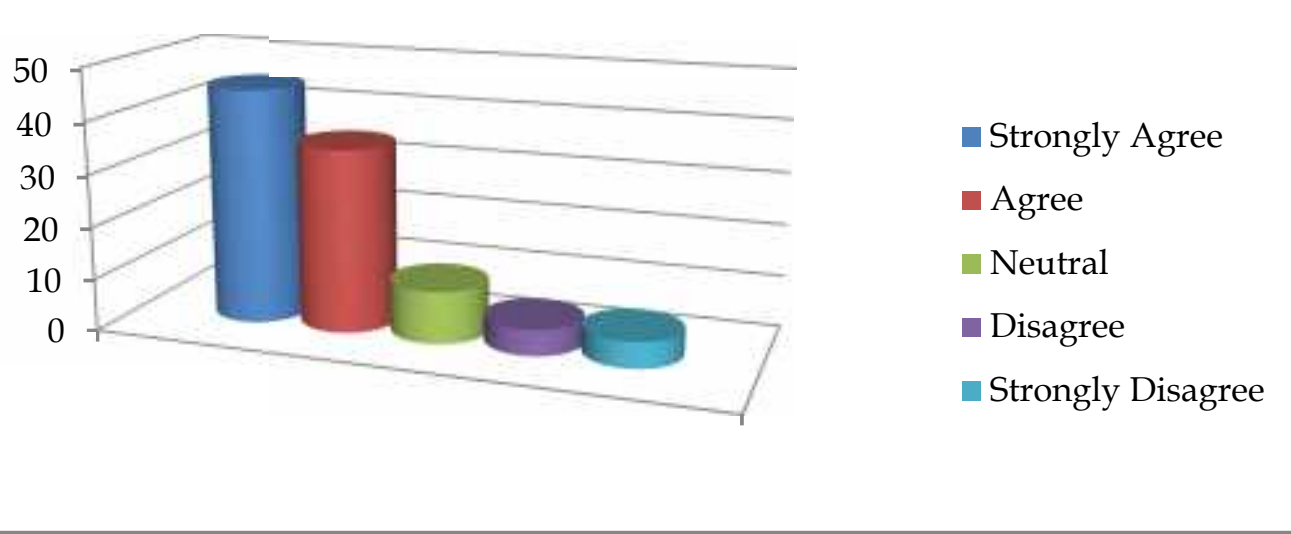

Figure 1: Attraction towards TV commercials having different writing style 
Figure 1 shows the varied of 100 respondents for the construct whether respondents feel attracted towards advertisements or not. One can see that each response is recorded under its specific heading i.e. ranging from strongly agree to strongly disagree. Here we can view that $45 \%$ respondents strongly agree while $35 \%$ only agree that they are attracted towards television commercials which have different style of writing. On the other hand 10\% respondents showed their neutrality towards the statement while 5\% respondents disagree and strongly disagree separately.

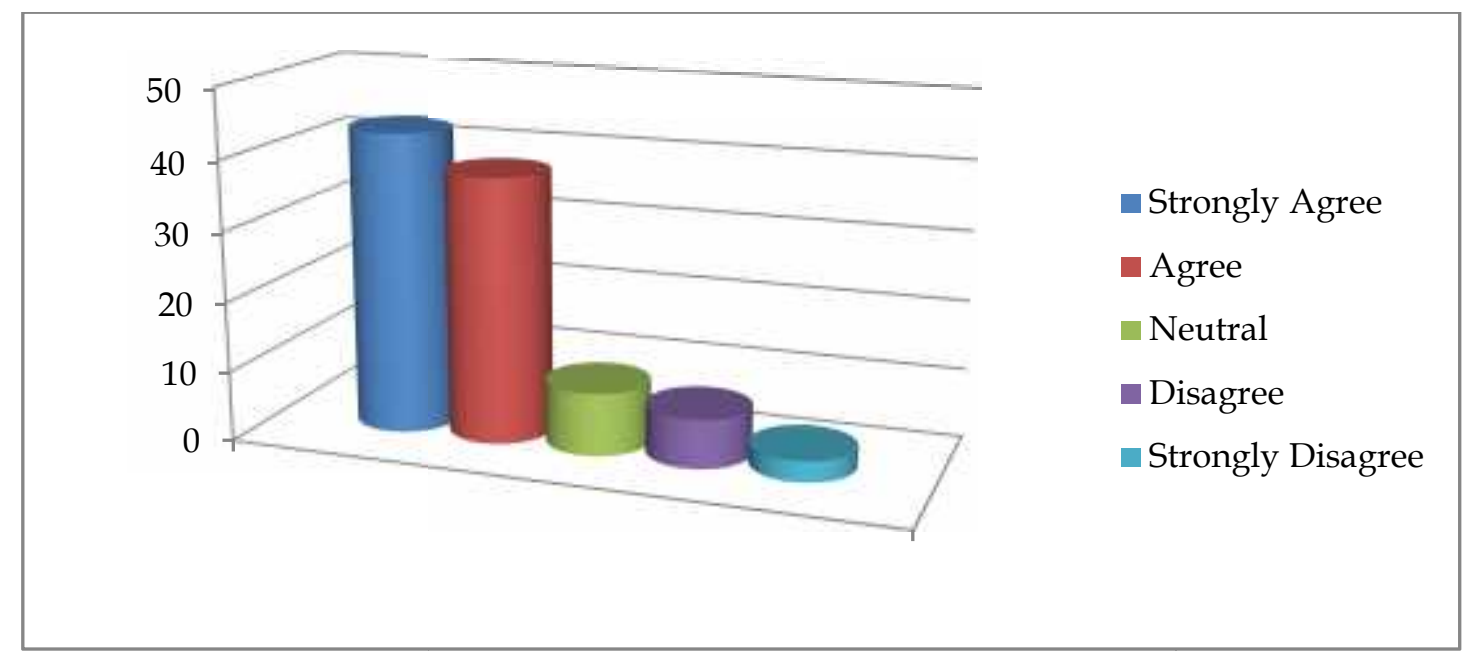

Figure 2: TV advertisements having different spellings catch attention immediately

Figure 2 indicates whether the respondents pay attention to different spellings used in television commercials or not. Different responses from the respondents regarding the construct suggest that $43 \%$ and $38 \%$ respondents strongly agree and agree respectively to the statement. On the other hand only $9 \%$ remain neutral,7\% disagree, and 3\% strongly disagree. The overall responses clearly suggest that majority of the people are in favor of the construct.

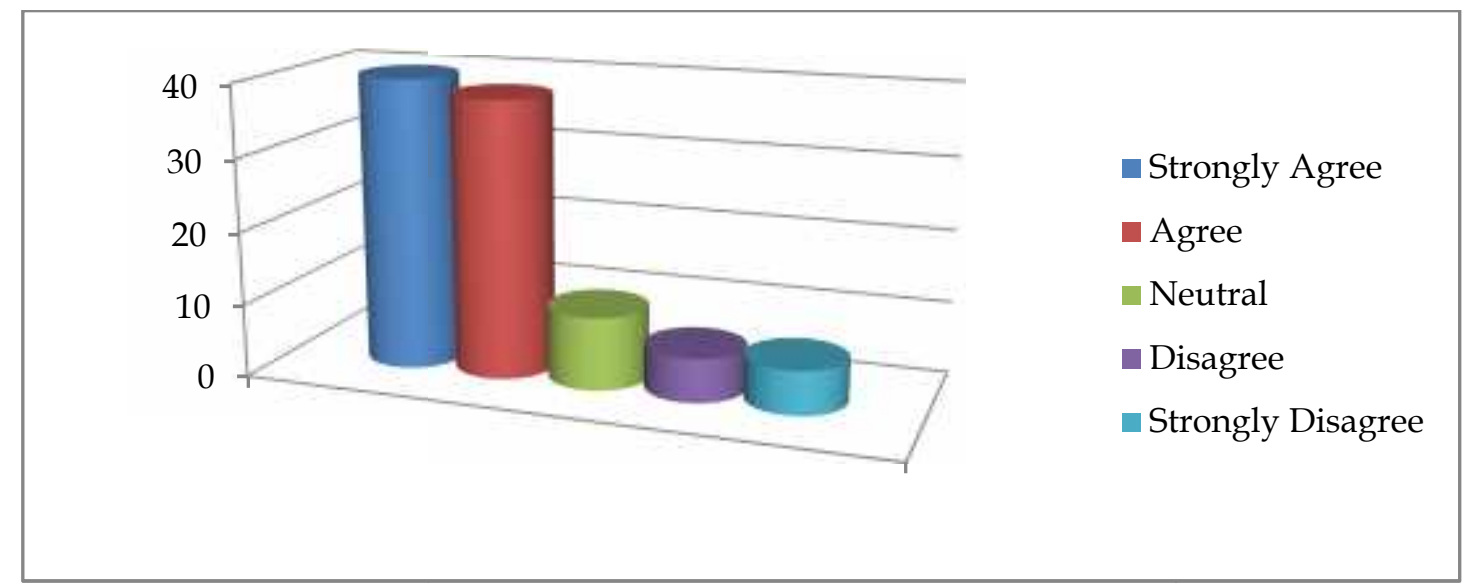

Figure 3: Unusual use of capitalization imprints in mind 
Figure 3, similar to the above figures 1 and 2, indicates that $40 \%$ respondents strongly agree $38 \%$ agree to the construct that unusual use of capital letters in TV commercials cast long lasting impression on the mind. On the other hand, $10 \%$ respondents remain neutral whereas the percentage of disagree and strongly disagree is 6 and 6 . The responses in the above graph represents that the respondents are in favor of the construct.

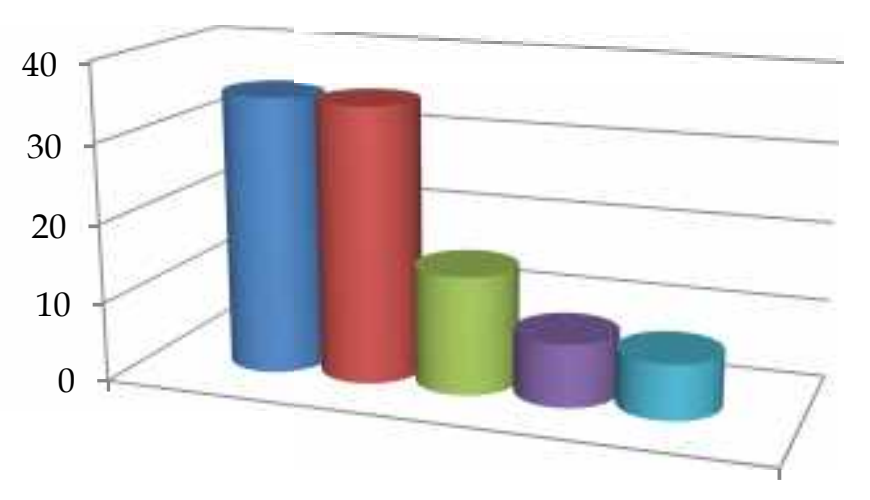

- Strongly Agree

Agree

Neutral

Disagree

- Strongly Disagree

Figure 4: TV commercials provide a sense of modernism

Figure 4 represents the responses of the participants of the current investigation towards the construct. The responses covering the range from strongly agree to strongly disagree. The figure under-discussion gives an idea that $35 \%$ respondents strongly agree and 35\% agree to the idea that TV commercials provide a sense of modernism. Contrary to it, only $15 \%$ participants remain neutral, $8 \%$ disagree and $7 \%$ strongly disagree to the construct.

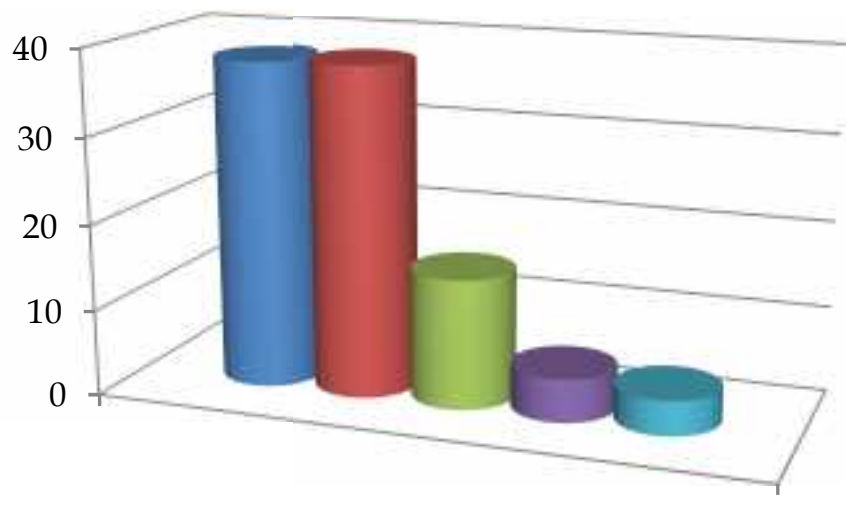

- Strongly Agree

- Agree

Neutral

- Disagree

- Strongly Disagree

Figure 5: Use of unusual spellings is a trendy aspect 
Figure 5 is a representation of the construct whether use of unusual spellings in TV commercials is a trendy aspect or not. The results indicate that $38 \%$ respondents strongly agree and $38 \%$ respondents agree that use of unusual spellings is a trendy aspect. On the other hand $15 \%$ respondents remain neutral whereas the percentage of disagree and strongly disagree responses are $5 \%$ and $4 \%$ respectively.

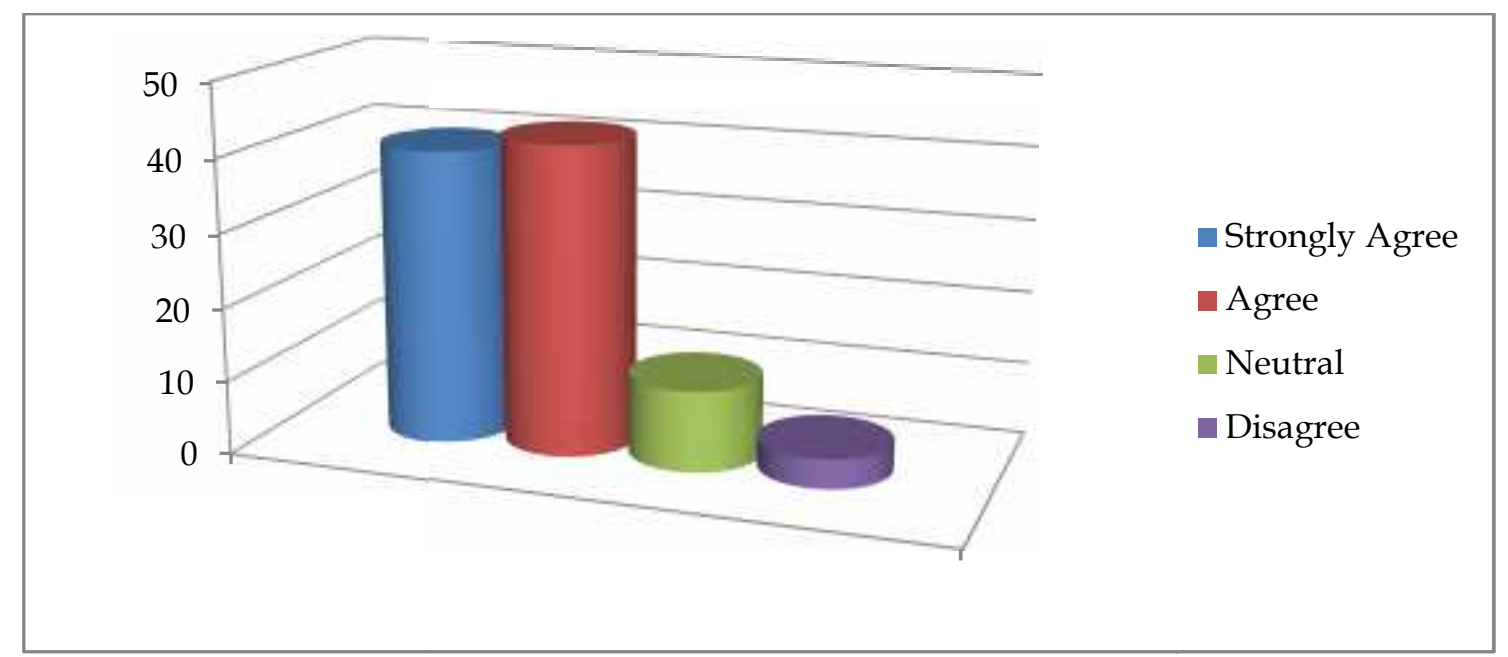

Figure 6: Mixing of two words to make one word looks innovative

Figure 6 indicates that $40 \%$ respondents strongly agree and $42 \%$ respondents agree to the construct whether mixing of two words to make one looks innovative or not. In response to this construct $11 \%$ respondents remain neutral. Furthermore only $4 \%$ respondents disagree and 3\% strongly disagree to the construct. The responses recorded in the above figure show that there is a variation in the replies of the respondents.

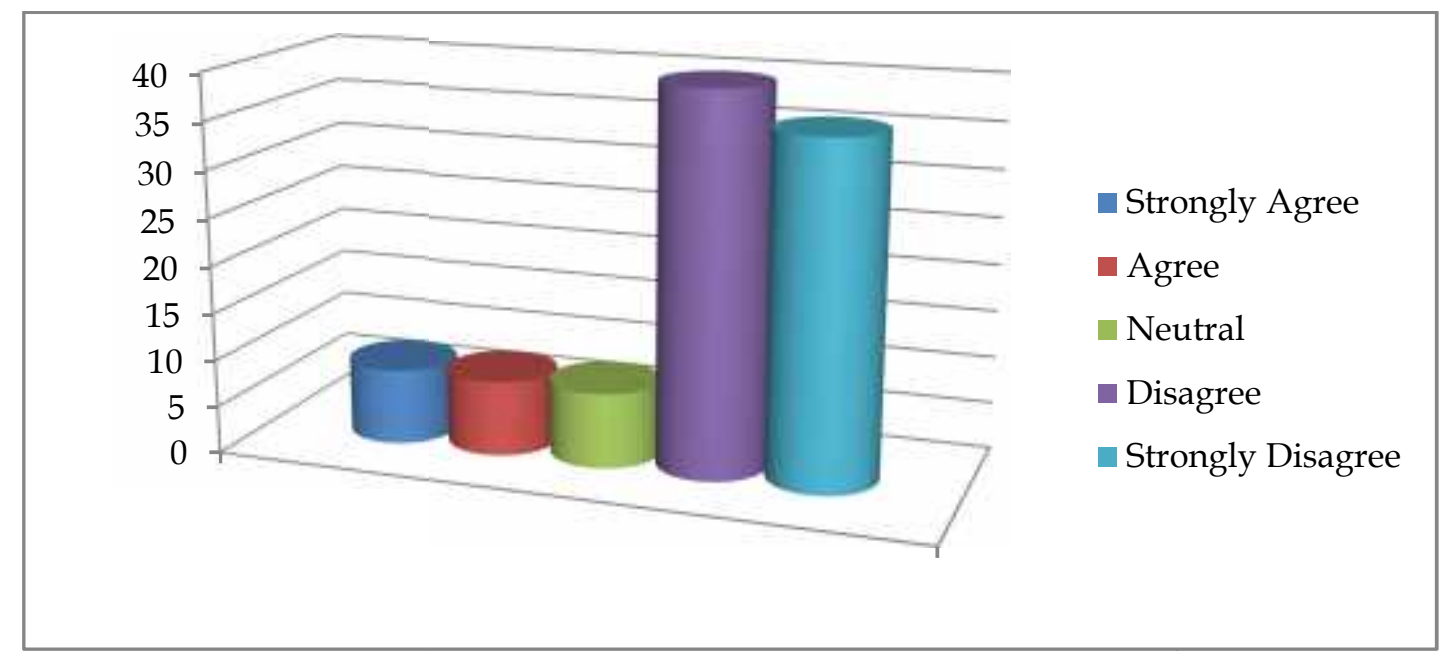

Figure 7: Preference of conventional language to new tendencies 
Figure 7 represents the responses of the respondents towards the idea that conventional language is preferable to new tendencies. Here each bar represents different opinion. The figure presented above suggests that $40 \%$ respondents strongly disagree and $36 \%$ respondents disagree to the construct. It also indicates that $8 \%$ participants remain neutral. On the other hand $8 \%$ respondents agree and strongly agree to the construct.



Figure 8: Mixing of two words to make one is never welcomed

Figure 8 shows the responses of the participants very clearly. The figure represents the collective responses but all these collective responses are mentioned under each bar distinctively. Here, it can be viewed that $35 \%$ respondents disagree and $35 \%$ strongly disagree to the construct that mixing of two words to make one is never welcomed. The less significant results are in favor of neutral, agree and strongly agree bars. Only 10\% respondents remain neutral. On the other side 9\% respondents agree and $10 \%$ participants strongly agree to the construct.



Figure 9: Irritation with the wrong use of capitalizations and spellings 
Figure 9 suggests the responses of the participants regarding the construct whether wrong use of capitalization and spellings is a source of irritation or not. The figure represents that $40 \%$ respondents disagree and 30\% strongly disagree to the construct. The less significant results are in favor of neutral, agree and strongly agree bars. Only $14 \%$ respondents remain neutral. On the other side $10 \%$ respondents agree and $6 \%$ participants strongly agree to the construct.

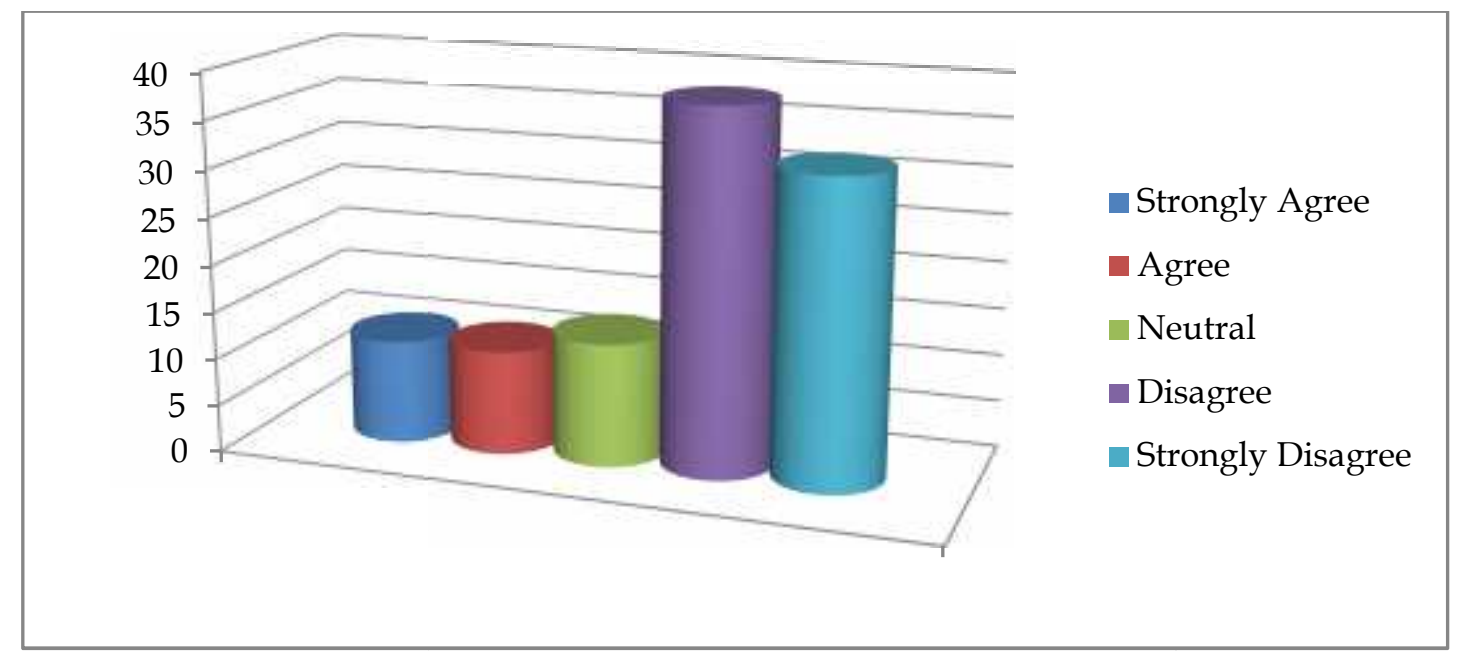

Figure 10: Against the use of any change in written language

Figure 10 indicates that $38 \%$ respondents disagree and 32\% strongly disagree to the construct that the respondents are against the use of any change in written language. On the other hand only 13\% respondents remain neutral while $11 \%$ respondents agree and $11 \%$ participants strongly agree to the construct.

Synthesizing and analyzing the results of the observation and questionnaire gives us a valuable insight into the phenomena of linguistic deviation in general and graphological deviation in particular.

The results accrued through observation suggest graphological deviation is a prevalent feature of Pakistani TV commercials. The norms of language are deviated consciously. It has been found that graphological deviation is done by using catchy words, alteration, capitalization etc. The chief purpose behind this type of deviation is to attract spectators' attention.

The results gleaned through questionnaire clearly state that the respondents have expressed their opinion bluntly and explicitly. In all the constructs we find very less percentage of those participants who remained neutral towards question. In the entire 10 statements one can see that respondents are either inclined towards the statements or they are against them. One can see that majority of the people living in Lahore are attracted towards the deviation in language. They are aware of graphological deviation and this is not a new concept for them. An important thing is that in no question we find equal percentage or balanced percentage; rather in all 
constructs we find percentage either very high or very low. It reflects the mindset of participants that they are quite aware of the changes, happening around the world. Not only they are attracted towards these changes in written language of advertisement but they also accept it with open heart. The results suggest that the ongoing trend of graphological deviation is catchy and appealing. This appreciation also keeps the advertisement writers alive and aware of the fact that the public is accepting, understanding and getting inspired by this kind of graphological deviations. The increased percentage of these deviations also reflects that very few people are showing negative reaction towards the deviation in English writing or Urdu roman writing.

Thus the overall findings propose that graphological deviation in TV advertisements is now a regular feature of Pakistani culture. It is welcomed, accepted and adored by the people living in Lahore. The results of this study are identical to the result of the study conducted by Rahman, T. (1990)in which it was stated that the linguistic deviation is a trend and it is being used as a stylistic element in the genre of Fiction in Pakistan. The results of this particular study are also similar to the findings produced by Sharma, R. (2015) who suggested that the advertising messages related to beverages and chocolates do deviate in graphological way. And it creates a positive impact on the mentality and psychology of Indian children. The outcomes are also in agreement to the study conducted by Nekongo, R. N. (2017) who indicated that the linguistic features and the deviation in linguistic features in advertisements always creates a positive impact on the minds of the viewers and they become attracted towards them. So a number of studies have found out that the writers try to deviate from the rules of writing to make it impactful, attractive and trendy. Chi, R., \& Hao, Y. (2013)

\section{Conclusion}

The role of advertisement has been to apprise the consumers, provoke their level of curiosity and to urge them to get more knowledge about the product. So graphological deviations are helpful for both who do these deviations and for those who watch them in commercials. Weir (1960) is of the view that a good strategy for selling products is to poeticize the products used by consumers.

This research also gives us an idea that now in the world of technology and globalization no culture can be unaware of the changes happening in the world. This research provides us an understanding of the people of Pakistan that though they are not only fully aware of the concept of graphological deviation yet they unknowingly like all the features of graphological deviations. They are aware that graphological changes are introduced just to catch the attention of the viewer so that the sale and popularity of a particular product may be increased.

The findings of the current study have its implications for researchers interested in linguistic or graphological deviations, script writers of TV commercials, and consumers or viewers of TV commercials. The researchers can find various gaps 
in the knowledge related to the language used in TV commercials. They can conduct more research studies in this area of investigation. The script writers may find this study insightful in using language in the commercials showing graphological deviations. The consumers or TV viewers too can know the phenomenon of graphological deviations and its purposes through the current study.

As far as linguistic or gaphological deviations are concerned future research deems necessary. Firstly, the same study can be conducted with more TV commercials and with larger sample. Secondly, besides TV commercials, poems etc. other genres showing graphological deviations like advertisements found on social media, advertisements through billboards, and commercials printed in print media can be investigated to have a deep insight into the phenomena. 


\section{References}

Ajiroghene, O., \& Umukoro, M. (2015). The Relevance of Graphological Markers Of Some Print Advertisements In Warri Metropolis. International Journal of Research, 9(1) 36-46.

Bulmer, M(2004). Questionnaires, 1st edition, Sage Benchmarks in Social Science Research Methods, edited by: Bulmer, M., Sage Publications, London.

Catherine M.,\& Gretchen, B. Rossman (1989). Designing Qualitative research. Newbury Park, CA: Sage Publications,

Chi, R., \& Hao, Y. (2013). Language deviation in English advertising. Studies in Literature and Language, 7(2), 85.

Chomsky, N. (1957). Syntactic Structures, The Hague, Mouton and Company

Edward, S. (1921). Language: An Introduction to the Study of Speech. Harcourt, Brace and Company, New York

Eva, Gomez-jamez, (2015). A Introduction to graphology: definitions, theoretical background and levels of analysis. miscelánea: A journal of English and American studies 51.

Fox, N., Hunn, A. \& Mathers, N. (2009). Sampling and sample size calculation. http://www.rds-eastmidlands.nihr.ac.uk/resources/doc_download/9sampling -and-sample-size-calculation.html

Geiser, S. \& Studley, R. (2001). Relative contribution of high school grades, SAT I and SAT II scores in predicting success at UC: Preliminary findings. Unpublished manuscript, University of California http://www.ucop.edu/sas/research/researchandplanning/pdf/sat_study.pdf

Guyette, S. (1983). Community Based Research: A handbook for native Americans. Los Angeles: University of California.

Halliday, M. A. K., McIntosh, A., Strevens, P. (1964). Linguistic sciences and language teaching. Bloomington: Indiana University Press.

Haulofu, L. T. (2017). A stylistic analysis of English online advisements by telecommunication providers: a case study of MTC and TN mobile (Doctoral dissertation, University of Namibia).

Raj,J. (2015). Linguistic Analysis of Advertising Communication: Phonological \& Graphological Deviations. International Journal of Enhanced Research in Educational Development (IJERED), 3 (1), pp 40-42 
Leech, G. (1966). English in advertising. London: Longman.

Leech, G., M. Short (1981) Style in Fiction London: Longman

Leech, Geoffrey. (1969). A Linguistic Guide to English Poetry. London \& New York: Longman

Mahmud \& Mahmud, (2017). Linguistic Effects on Television Advertisement: A Stylistic Approach. Research on Humanities' and Social Sciences, 7(14).

Mcintosh (1961).Graphology and meaning McIntosh Angus, 13 pp 107-120

Nekongo, R. N. (2017). An analysis of linguistic features of male cosmetics advertisements from FHM (For Him) and GQ (Gentlemen's Quarterly) magazines (Doctoral dissertation).

Prakash, A., \& Dhawan, A. (2017). Linguistic Divergences in Newspaper Headlines. International Journal of Engineering Technology Science and Rresearch, 4(7), 858-864.

Rahman, T. (1990). Linguistic deviation as a stylistic device in Pakistani English fiction. The Journal of Commonwealth Literature, 25(1), 1-11.

Saleem, M. (2012). Analysing graphological deviations in TS Eliot's Poem AshWednesday. Language in India, 12(3).

Sharma, R. (2015). Linguistic deviations in advertising messages of chocolates and beverages: It's impact measurement on the psychology of children in India (Doctoral dissertation, BITS Pilani).

Suphat, S. (2007). Fundamentals of quantitative research https://www.researchgate.net/researcher/2015730042_Suphat_Sukamolson

Walter, W. (1960). On the writing of advertising. New York: McGraw Hill Book Company, Inc.

Wen, Q. (2014). Aristotlees Definition of Language. International Journal of English Literature and Culture 2(8) pp194-202

Widayanti, S. R. (2014). A stylistic study of language deviation in Thomas Hardy's The Ruined Maid. MAGISTRA, 26(90), 53. 